\title{
Концепция информационной системы мониторинга пассажиропотоков общественного транспорта городских агломераций
}

\author{
Д.В. Петрова \\ МИРЭА-Российский технологический университет \\ Darina200896@ma i I.ru
}

\section{Аннотация}

В данной статье описывается концепция информационной системы мониторинга пассажиропотоков общественного транспорта городских агломераций. Рассматривается специфика транспортной инфраструктуры городской агломерации Москвы, её особенности и основные проблемы. Для решения рассмотренных проблем предлагается разработка и внедрение информационной системы мониторинга пассажиропотоков Московской агломерации. Кроме того, рассматриваются аналоги предлагаемой системы мониторинга, а также приводится перечень основных показателей мониторинга пассажиропотоков и их применение.

Ключевые слова: информационная система, мониторинг, пассажиропоток, транспортная инфраструктура, транспорт, городские агломерации

Библиографическая ссылка: Петрова Д.В. Концепция информационной системы мониторинга пассажиропотоков общественного транспорта городских агломераций // Информационное общество: образование, наука, культура и технологии будущего. Выпуск 3 (Труды XXII Международной объединенной научной конференции «Интернет и современное общество», IMS-2019, Санкт-Петербург, 19-22 июня 2019 г. Сборник научных трудов). - СПб: Университет ИТМО, 2019. С. 27 - 40. DOI: $10.17586 / 2587-8557-2019-3-27-40$

\section{Введение}

Тематика городских агломераций, их развитие и состав является достаточно актуальной для изучения. Первой причиной такого внимания стало стремительное увеличение числа городских агломераций по всему миру. Второй причиной стали результаты многочисленных исследований, подтверждающие сильное влияние современного этапа развития общества на сжатие социально-экономического пространства, увеличение концентрации населения и хозяйственной деятельности на территории крупнейших городов и их периферийных зонах [1].

Жизнь городских агломераций тесно связана с уровнем развития её транспортной инфраструктуры. Она требует особого внимания, так как является частью не только производственной и экономической, но и социальной инфраструктуры. За счет нее в городских агломерациях каждый день реализуются перевозки грузов и пассажиров. Она является связующим звеном между населением и производством, выступая средством ежедневных трудовых маятниковых миграций населения между жильем и работой. От эффективности работы системы перевозки пассажиров внутри городских агломераций зависит скорость передачи рабочих ресурсов, и, как следствие вся экономическая сфера жизни города. Кроме того, без продуманной системы пассажироперевозок невозможно построить и социальную сферу. 
Формирование стратегических направлений развития транспорта должно осуществляться на базе всестороннего анализа современного состояния и проблем развития транспортной системы в тесной взаимосвязи с общими направлениями и масштабами социально-экономического развития страны, а также с глобальными общемировыми стратегическими тенденциями в экономике. В сфере транспорта в России в последние годы была проведена необходимая модернизация инфраструктуры, что позволило удовлетворить растущий спрос на пассажирские и грузовые перевозки и создать определенный задел для дальнейшего развития [2].

Эффективная работа транспортной инфраструктуры возможна только в случае своевременного реагирования на изменения её текущего состояния. В данном случае наиболее эффективно отслеживать происходящие изменения в реальном времени, что даст возможность незамедлительно реагировать на них. Отслеживание состояния работы транспортной системы в реальном времени возможно только при помощи внедрения единой информационной системы мониторинга. Такие информационные системы и их интеграция является неотьемлемой частью концепции «умного» города, в частности вводится понятие «умного транспорта». «Умный город» - это концепция информатизации города, включая интеграцию всех коммуникационных и информационных технологий с целью эффективного управления городской системой. Современные технологии в условиях «Умного» города позволяют решить задачу оперативного сбора и передачи данных государственному аппарату, рациональное использование всех объектов городской инфраструктуры, а также комплексное благоустройство среды. Концепция «Умный» город характеризуется использованием различных технологий, к которым относятся беспроводные сенсорные сети, IоТ датчики, онлайн-платформы, электронные карты и приложения [3], [4]. Кроме того, «Умный» город характеризуется установлением тесных связей между городским управленческим аппаратом и местными жителями [3], [4].

На сегодняшний день существует широкий спектр систем, позволяющих осуществлять мониторинг пассажиропотоков городских агломераций. Однако, ни одна из них не реализует всеобъемлющий доступ к информации, как для городской власти и юридических лиц, так и для конкретных потребителей, в лице граждан. Кроме того, практически не одна из существующих разработок не интегрируется с другими системами через единое информационное пространство, что не позволяет им в полной мере встроится в городскую информационную экосистему. В то же время практически полностью отсутствуют системы, специализирующиеся на мониторинге пассажиропотоков именно общественного транспорта в пределах агломерации.

Таким образом, актуальной является задача внедрения единой ИС, позволяющей осуществлять мониторинг пассажиропотоков городских агломераций в режиме реального времени. Для построения единого информационного пространства необходимо, чтобы внедряемая информационная система отвечала следующим критериям: осуществляла мониторинг состояния транспортной инфраструктуры агломерации в реальном времени; имела низкую погрешность при анализе ключевых показателей пассажиропотоков; осуществляла мониторинг всех видов общественного транспорта; была интегрирована с существующими информационными системами «Умного» города; была аддаптирована для всех групп пользователей (физических лиц, юридических лиц и государственных служащих); была доступна с большинства современных платформ. На данном этапе развития транспортной сферы страны, внедрение подобной системы, на наш взгляд, наиболее актуально в условиях развития города Москвы и его агломерации.

Целью данной статьи является формулирование концепции информационной системы эффективного мониторинга пассажиропотоков городских агломераций в условиях «умного» города, для постановки задачи на внедрение подобной ИС, а также ее проектирование и разработку в случае отсутствия реализации подобной системы на рынке. 
Для достижения данной цели были поставлены следующие задачи:

1. Исследовать предметную область городских агломераций «умных» городов и их транспортные системы.

2. Выявить проблемы и недостатки транспортной отрасли городских агломераций.

3. Проанализировать существующие системы мониторинга пассажиропотоков, их возможности и недостатки.

4. Предложить концепцию информационной системы мониторинга пассажиропотоков городской агломерации.

Концепция, которая описывается в данной статье будет полезной для разработчиков, проектирующих и разрабатывающих систему мониторинга пассажиропотоков городской агломерации, для аналитиков, а также органов власти для построения современной транспортной системы, отвечающей требованиям концепции «умного» города.

\section{1. Городские агломерации и их транспортные системы}

В современном мире города стремительно заменяют села и посёлки, сращиваясь в единые агломерации. Согласно статистике Росстата, доля городского населения составляет практически 74\% [5], это в свою очередь говорит о том, что роли крупных городов и их окрестностей увеличиваются, объединяясь в агломерации, тем самым концентрируя промышленный и технологический потенциал, вносящий крупный вклад в ВВП страны [6].

Городская агломерация - представляет собой компактное скопление городских населённых пунктов, объединённых в сложную многокомпонентную динамическую систему с интенсивными производственными, транспортными и культурными связями.

Городские агломерации являются неотъемлемой частью социально-экономического развития страны, которая оказывает влияние на экономику не только внутри своей территории, но и на соседние субъекты [6].

Развитие городских агломераций безусловно является эволюционной тенденцией человечества. Однако, при всех положительных моментах развития производства, науки, культуры и экономики существует достаточно большое количество недостатков, которыми характеризуются городские агломерации. Одним из наиболее значимых недостатков является тот факт, что транспортно-логистические схемы не всегда обеспечивают должный уровень скорости перевозок грузов и людей. Кроме того, существенную нагрузку на транспортную инфраструктуру городских агломераций оказывает большой приток работоспособного населения, привлекаемый из малых городов спутников. В целом, это влечет дополнительные сложности при административном управлении транспортной инфраструктурой [7].

Население, как определяющий компонент функционирования экономики, обеспечивает производство трудовыми ресурсами и формирует спрос для рынка. Как следствие, показатель мобильности населения внутри агломерации, является основным показателем эффективности ее транспортной инфраструктуры.

С учетом существенного роста доходов населения, расширения территориальных возможностей приложения труда и выбора жилья подтверждается исключительное значение транспортной инфраструктуры. Пределы пространственного взаимодействия всех элементов системы и, в особенности, интенсивность ежедневных миграционных потоков лимитируют предельные возможности транспорта [8].

Перегрузка транспортных систем является прямой угрозой всем сферам жизни города. Интеграция транспортных систем создает преимущества, как для поставщиков, так и потребителей транспортных услуг.

Самой крупной из городских агломераций России является столичная агломерация. Московская агломерация является компактно расположенной группой городских и сельских поселений, объединённых интенсивными и многообразными хозяйственными, трудовыми, производственными, культурно-бытовыми взаимосвязями в сложную 
многокомпонентную динамичную систему с центром в городе Москве. Московская агломерация - это крупнейший в России макроэкономический регион, который также занимает место в двадцатке самых крупных мировых агломераций (16,8 миллиона человек). В настоящее время агломерация не так сильно централизована, как была в 1980-х годах, однако, сам город Москва, как центр агломерации, так и страны в целом, является ядром Московской агломерации. По прогнозам на 2025 год численность населения столичного региона может достичь 21 миллиона жителей. В московскую агломерацию входят более 70 городов, некоторые из которых насчитывают население более 100 тысяч человек [6].

Основой транспортной инфраструктуры Москвы, является Московский метрополитен, наземный городской пассажирский транспорт (автобусы, трамваи, троллейбусы), Московское центральное кольцо, железнодорожный транспорт, Московская монорельсовая транспортная система и такси [9].

Для управления всей транспортной инфраструктурой необходимы не только современные системы управления, но и целые институты. Вопросами обеспечения населения города Москвы общественным транспортом, занимается «Департамент транспорта и развития дорожно-транспортной инфраструктуры города Москвы». Департамент формирует политику, предоставляет услуги, управляет государственным имуществом в сфере транспорта и развития дорожно-транспортной инфраструктуры, обеспечивает его безопасность.

Согласно статистике, приведённой в официальном отчете Департамента транспорта Москвы, за 2018 год на городском транспорте в будний день совершалось более 19 млн поездок в сутки. Пассажиропоток экономически активных граждан, которые оплачивают свой проезд, в 2018 составил 3,7 млрд. поездок. А также доля людей, пользующихся городским транспортом, составила на 2017 год 68 \% [10].

Основными факторами, которые влияют на транспортную инфраструктуру Москвы являются:

— высокая плотность населения;

- большое количество туристов, число которых резко возрастает в периоды праздников;

— «маятниковая миграция» рабочей силы, утром потоки направляются к центру города, а вечером - обратно;

— большое количество частного транспорта;

- резкое увеличение количества пассажиров общественного транспорта в пиковые часы нагрузки, что дополнительно осложняется резким увеличением загруженности дорог частным транспортом;

- отсутствие маршрутных такси;

- в районах, где отсутствует метрополитен, в пиковые часы нагрузки общественный транспорт перегружен.

Современные транспортные сети крупных городов и городских агломераций состоят из огромного количества подсистем и структурных элементов; характеризуются огромным количеством ключевых величин, и как следствие постоянно порождают огромное количество информации. Эффективное управление современными транспортными системами возможно только при полноценном сборе информации на каждом участке сети и её своевременном детальном анализе. Эффективное внедрение современных технологий во все сферы жизни города в целом и в транспортную систему в частности, в конечном итоге позволит воплотить концепцию «умного» города в современных реалиях такой городской агломерации как Московская.

\section{2. Проблемы в транспортной сфере Московской агломерации}

Наиболее важные проблемы развития общественного транспорта столичной агломерации часто связаны с районами проживания населения и происходят, когда 
транспортные системы, по целому ряду причин, не могут удовлетворять многочисленным требованиям городской мобильности. Среди заметных проблем городского общественного транспорта основными являются:

— недостаточный объём собираемых и обрабатываемых данных по актуальному состоянию транспортной сети;

— недостаточное оборудование транспортных средств системами контроля и учета;

- трудности парковки общественного транспорта на остановочных пунктах;

- сокращение общественного (муниципального) пространства из-за высокого и интенсивного пассажирского трафика;

— недостаточно высокое качество услуг общественного транспорта, включая низкую скорость его движения и высокую загруженность в часы пик;

- отсутствие эффективного мониторинга пассажиропотоков городской агломерации, и как следствие ухудшение качества прогнозов.

Кроме того, Департаментом транспорта Москвы были выявлены следующие ключевые проблемы [9]:

1. Плотность населения Москвы (100 человек/га) превышает аналогичный показатель крупнейших мегаполисов мира.

2. Плотность улично-дорожной сети (3,38 км/кв. км) в 24 раза ниже аналогичных показателей крупнейших мегаполисов мира.

3. Фактическая загрузка всех видов общественного транспорта в утренние часы «пик» при движении в центр составляет 1,060 млн. человек и превышает провозную способность (870 тыс. человек) в среднем на $22 \%$.

4. Загрузка автомобильных дорог превышает их пропускную способность на $42 \%$.

5. Среднее время поездки на общественном транспорте пассажира из жилых районов до «мест приложения труда» составляет 67 минут, а около 20\% жителей г. Москвы тратят более трех часов в день на дорогу от дома до работы и обратно.

6. При наименьшей протяженности линий метрополитена объем перевозок в 1,5-2 раза превышает аналогичные показатели крупнейших мегаполисов мира, средняя наполняемость вагонов электропоездов метрополитена составляет 5,2 человека/кв. м.

7. Недостаточное развитие наземных видов общественного транспорта, низкая плотность маршрутной сети, отсутствие преимуществ для движения общественного транспорта в транспортном потоке.

8. Слабая система хордовых связей между радиальными автомобильными дорогами.

9. Отсутствие дублирующих направлений магистральных радиальных автомобильных дорог, их недостаточная пропускная способность и несоответствие параметров автомобильных дорог на границе Москвы и Московской области планировочным параметрам.

10. Недостаточный уровень технического состояния искусственных сооружений и проезжей части на значительном протяжении автомобильных дорог федерального и регионального значения.

11. Отсутствие транспортных развязок на разных уровнях на пересечениях уличнодорожной сети, в том числе с железными дорогами и реками.

12. Отсутствие эффективной системы управления дорожным движением.

13. Недостаточное взаимодействие перевозчиков, обслуживающих автобусные маршруты, отсутствие скоординированной системы управления перевозками, использующей современные средства глобального позиционирования.

14. Неполная приспособленность транспортной инфраструктуры городских агломераций к нуждам маломобильных групп населения.

Одной из ключевых проблем отрасли общественного транспорта городских агломераций является загруженность автомобильных дорог. На сегодняшний день широкое распространение получают специальные выделенные полосы для общественного транспорта на дорогах. 
Должного развития не получает городской общественный транспорт, в том числе его современные скоростные виды, которые могли бы существенно снизить остроту проблемы транспортного развития мегаполисов.

Развитие транспортной инфраструктуры городских агломераций не успевает за стремительно растущим количеством автомобилей. Требуются дополнительные меры по сдерживанию роста автомобилистов и стимулированию использования общественного транспорта.

В свою очередь, недостаточный объём собираемых данных не позволяет в должной мере прогнозировать состояние транспортной сети в будущем. Ключевым моментом для получения актуальной информации о состоянии транспортной сети городской агломерации в текущий момент времени является непрерывный сбор данных с каждого конкретного участка сети и их своевременная передача в единый центр обработки данных (ЦОД). Для этого необходимо каждое транспортное средство и участок транспортной сети оборудовать системами измерения ключевых показателей пассажиропотока, и непрерывно собирать с них (систем измерения) актуальную и достоверную информацию для дальнейшего анализа.

Сегодня, все вышеперечисленные проблемы могут периодически проявлять себя на каждом из маршрутов транспортной сети. Наиболее эффективным является борьба с этими локальными проблемами на этапе их возникновения. Это позволяет решить малую локальную проблему до момента ее перерастания в глобальную, оказывающую влияние на пассажироперевозки в городе в целом. Кроме того, зачастую, устранить такие «малые» проблемы возможно быстро, затратив минимальные ресурсы. Однако, наиболее сложным, в данном случае, является своевременное обнаружение подобного рода угроз.

Для обнаружения проблем функционирования транспортной системы в момент их возникновения необходимо иметь доступ к информации о состоянии всей транспортной инфраструктуры в реальном времени. Этого возможно достичь только при внедрении единой информационной системы мониторинга пассажиропотока общественного транспорта городской агломерации в целом.

\section{3. Существующие технологии мониторинга пассажиропотока}

Сегодня на Российском рынке начали появляться различные технологии для мониторинга пассажиропотоков общественного транспорта с помощью специальных датчиков и центров обработки данных с них. Такой подход возможет только при построении распределённой системы сбора актуальных и достоверных данных о состоянии транспортной сети. Распределенность системы налагает дополнительные ограничения на магистрали передачи данных, а также затрудняет их своевременную доставку в ЦОД. Несмотря на это, реализовать такую концепцию системы распределённого сбора данных возможно при внедрении современных технологий «умного» города: сетей передачи данных поколения $4 \mathrm{G}$ и $4 \mathrm{G}+$, а также «умных» IоT датчиков и контроллеров.

Такие датчики могут быть выполнены в виде: 3D-камер видеонаблюдения, датчиков инфракрасного излучения, специальных тензодатчиков встроенных в ступеньки транспортных средств и др. В основном эти технологии предназначены для мониторинга пассажиропотока междугороднего общественного транспорта дальнего следования, курсирующего между населенными пунктами. Существуют и информационные системы мониторинга, использующие ту или иную технологию для снятия показателей пассажиропотока. Рассмотрим несколько из них.

Система мониторинга пассажироперевозок «ПОТОК» предназначена для сбора информации об интенсивности перевозок пассажиров на наземном транспорте, посредством учёта количества пересечений пассажирами дверных проёмов, контролируемых инфракрасными датчиками системы [11], [12]. 
Данная технология позволяет решить следующие проблемы:

- расчет пассажиропотока, его распределения в течение дня, недели и года;

— определение места наибольшей концентрации пассажиров;

— определение среднего расстояния поездки;

- определение наиболее загруженных направлений;

— расчет точной оценки загруженности маршрута;

- и другие.

Технология мониторинга пассажиропотока общественного транспорта от компании «Евромобайл» на основе технологий распознавания лиц. Технология представляет собой комплексную систему учета пассажиропотока, в основе которой находятся датчики с двумя встроенными видеокамерами. Камеры распознают лица пассажиров и передают данные по сети ETHERNET или интерфейсу RS485 на бортовой контроллер, установленный в транспортном средстве. Подсчет пассажиров происходит за счет 3Dанализа лиц. В свою очередь контроллер передаёт данные о зашедших и вышедших пассажирах на сервер мониторинга по сети 2G/3G [13].

Отличительной особенностью данной технологии является то, что при мониторинге система не учитывает статичные и крупные объекты, например, поручни и коляски и не считает дважды пассажиров, которые вышли из автобуса, чтобы выпустить выходящих пассажиров. Данная технология может использоваться на всех видах транспорта. Позволяет выявить моменты пиковой и нулевой загрузки и соотнести их с геопозицией транспорта; определить местонахождения пассажиров в режиме реального времени.

Система подсчёта пассажиропотока (СПП) от компании «АльфаВладТелематика», позволяющая контролировать количество перевозимых пассажиров в городском наземном транспорте (рейсовые или маршрутные автобусы, троллейбусы, трамваи, маршрутные такси) в режиме реального времени. Предоставляется возможность контролировать водителей и кондукторов, планировать оптимальное количество транспортных средств на маршруте с учётом его загруженности. Помимо основной функции подсчёта пассажиров система мониторинга позволяет определить точное количество произведенных рейсов в течение заданной даты по каждому борту / рейсу; время посещения остановок; отклонения от заданного графика на определенную дату по всему маршруту [14].

СПП как правило, состоит из бортового абонентского терминала, сумматора (вычислительного блока) и подключённых к нему специальных датчиков, устанавливаемых в салоне автобуса, а также датчиков открытия/закрытия дверей. Возможно использовать два типа датчиков: датчики типа «ступень» и датчики типа «штора». Первые датчики работают по принципу реагирования на вес входящего пассажира, вторые - фотоэлектрические и используют принцип пространственного изменения среды при прохождении сквозь виртуальную штору человека (видеокамеры, ИК-датчики и ИК-излучатель) [14].

Одним из главных преимуществ системы является то, что на точность работы системы не влияют погодные условия и температура окружающего воздуха. Датчики типа «ступень» стабильно подсчитывают пассажиропоток даже будучи залитым водой или при замерзании снега и льда.

Сравним все вышеперечисленные системы по определёнными критерия, которые интересуют нас в первую очередь. В Таблице 1 приведено сравнение выбранных решений с предлагаемой системой.

Таким образом, проанализировав существующие технологии мониторинга пассажиропотоков городских агломераций было выявлено, что большинство технологий направлено на мониторинг междугороднего транспорта дальнего следования. Кроме того, многие технологии дают большую погрешность при мониторинге пассажиропотоков в периоды пиковой нагрузки транспорта, а также все системы мониторинга направлены на предоставление информации не для пассажиров, а для самих компаний, осуществляющих перевозку граждан. 
Таблица 1. Сравнительная таблица аналогов

\begin{tabular}{|c|c|c|c|c|}
\hline \multirow{2}{*}{$\begin{array}{c}\text { Критерии } \\
\text { сравнения }\end{array}$} & \multicolumn{4}{|c|}{ Рассматриваемые системы } \\
\cline { 2 - 5 } \% погрешности & $4,5 \%$. & Доток $10 \%$ & $2-3 \%$ & $\begin{array}{c}\text { Предлагаемая } \\
\text { ИС }\end{array}$ \\
\hline $\begin{array}{c}\text { Пользователи } \\
\text { системы }\end{array}$ & Юр.лицо & Юр.лицо & Юр.лицо & $\begin{array}{c}\text { Государство, } \\
\text { юридические } \\
\text { лица. } \\
\text { Физические } \\
\text { лица }\end{array}$ \\
\hline $\begin{array}{c}\text { Мониторинг } \\
\text { пассажиропотоков } \\
\text { в реальном } \\
\text { времени }\end{array}$ & - & + & & + \\
\hline $\begin{array}{c}\text { Наличие } \\
\text { мобильного/веб- } \\
\text { приложения для } \\
\text { граждан }\end{array}$ & - & - & & + \\
\hline $\begin{array}{c}\text { Определение } \\
\text { безбилетников }\end{array}$ & - & & & + \\
\hline $\begin{array}{c}\text { Вид транспорта } \\
\text { для мониторинга }\end{array}$ & Междугородний & Любой & Междугородний & \\
\hline
\end{tabular}

\section{4. Концепция ИС мониторинга пассажиропотоков городских агломераций}

Проанализировав существующие технологии мониторинга пассажиропотоков, было обнаружено, что они не обладают достаточной эффективностью и функциональностью для их повсеместного внедрения в транспортную инфраструктуру такой крупной агломерации как Московская. Также, описанные системы представлены в виде В2В решений. На наш взгляд в современной системе должно быть реализовано единое информационное пространство как для государства и юридических лиц, так и для граждан - пассажиров общественного транспорта. Такое информационное пространство должно быть реализовано в виде единой информационной системы мониторинга пассажиропотоков Московской агломерации. Проектируемая система мониторинга, должна являться, в первую очередь, распределённой измерительной системой, основным отличием которой от традиционных измерительных систем является возможность использования различных типов датчиков без изменения общей структуры и наличие средств управления данными от этих датчиков, что позволяет системе адаптироваться к динамически изменяющимся условиям, среди которых могут быть требования к функционалу, отказоустойчивости и масштабируемости системы [15].

Система должна предоставлять возможность в режиме реального времени отслеживать состояние пространственно-распределённого объекта наблюдения - транспортной сети Московской городской агломерации, анализировать причины нештатных ситуаций, а также осуществлять мониторинг пассажиропотоков транспортной сети.

Предполагается, что ИС мониторинга будет интегрирована с текущими, уже установленными системами сбора и обработки данных, а также позволит взаимодействовать с новыми перспективными системами, за счёт предоставления им 
доступа к публичному АРІ. Кроме того, ИС мониторинга пассажиропотоков должна быть интегрирована с системой оплаты проезда, установленной в каждом транспортном средстве, а также с информационной системой Департамента транспорта по мониторингу состояния транспортной сети и маршрутов.

При разработке концепции построения системы мониторинга было выделено 3 основных объекта [15].

Объект мониторинга - пассажиропотоки транспортной сети. Задается несколькими динамическими параметрами, характеризующими его состояние. Для регистрации значений этих параметров на объекте мониторинга должна быть развёрнута распределенная система измерения, состоящая из разных типов датчиков. Датчики в системе могут быть управляемыми, в этом случае возможна настройка датчиков системе удаленным пользователем.

Ядро системь мониторинга (сервер) - это некоторая программно- аппаратная часть системы, обеспечивающая хранение информации мониторинга, а также взаимодействие клиентов и объектов мониторинга. Сервер ядра системы должен своевременно обрабатывать огромное количество информации, непрерывно поступающей с распределённой системы измерения. Это возможно только при внедрении информационных магистралей большой пропускной способности, а также предоставляя большое количество вычислительных ресурсов на анализ поступающих данных.

Пользователи системы - конечный получатель информации мониторинга состояния транспортной сети. Также Пользователи могут выполнять удаленную настройку системы.

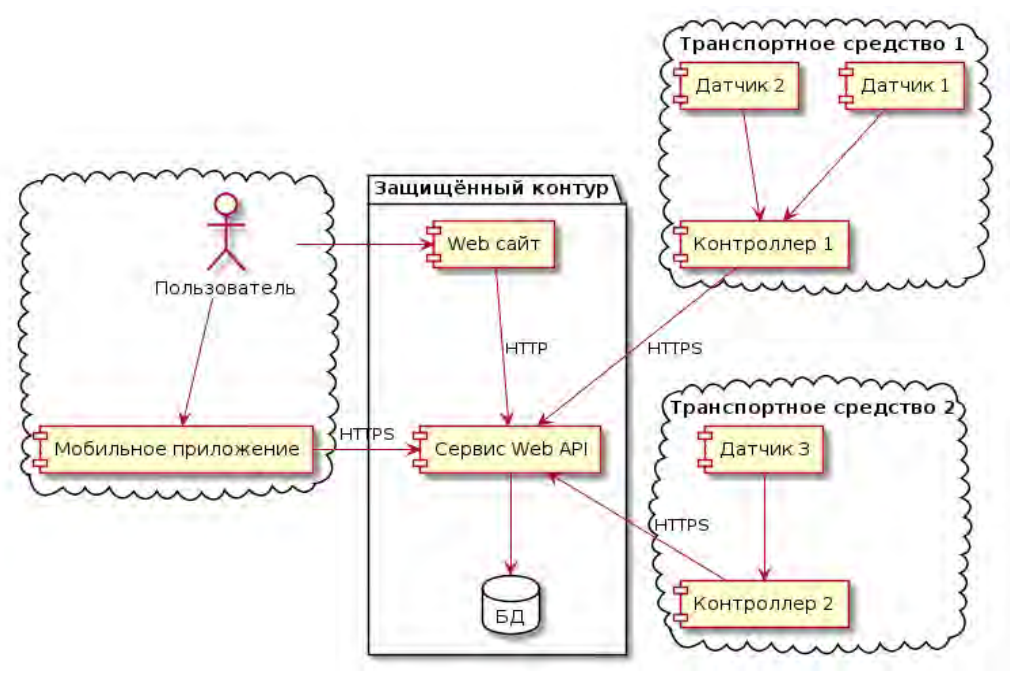

Рис. 1. Архитектура системы мониторинга пассажиропотоков

В системе можно выделить 3 уровня иерархии.

Уровень объекта. Представляет собой удаленную измерительную систему, состоящую из нескольких датчиков, распределенных по транспортному средству и контроллера. Функциями данного уровня являются регистрация данных датчиками, передача данных на контроллер, первоначальная их обработка на контроллере и передача по высокоскоростному защищённому каналу передачи данных. Основной проблемой данного уровня является объединение данных от нескольких датчиков в один высокоскоростной защищённый цифровой информационный поток. В качестве варианта ее решения предлагается использовать блок сбора данных (контроллер), представляющий собой многоканальный вторичный преобразователь сигналов датчиков и объединение их в один информационных поток по стандартному протоколу выходного интерфейса. 
Уровень сервера. Основной компонент сервера системы мониторинга - это серверное ПО, позволяющее объединять множество удаленных объектов мониторинга и конечных пользователей в единую информационную сеть. ПО включает сервер приложений, вебсайт, мобильное приложение (для обращения пользователей к системе) и базу данных. Основными функциями данного уровня являются прием данных с удаленной измерительной системы, расположенный непосредственно в транспортном средстве; ведение баз данных, регистрируемых датчиками; обработка и анализ принимаемых данных согласно требованиям; выборка и предоставление данных удаленным пользователям.

Уровень пользователя. В качестве пользователя системы может выступать пользователь веб-сайта или мобильного приложения, который желает получить доступ к оперативным данным системы мониторинга и результату анализа этих данных.

Основная идея построения единой системы мониторинга заключается в объединение пространственно-распределенных объектов мониторинга и пользователей, имеющих доступ к информации по этим объектам. На Рисунке 1 представлена архитектура системы мониторинга пассажиропотоков городской агломерации.

Для наибольшего удобства использования ИС клиентами и пользователями необходимо предоставить им возможность оперативного доступа к ИС. Сегодня, это возможно только при условии наличия точек входа в ИС со всех популярных платформ. То есть необходимо реализовать как веб-сайт, так и кроссплатформенное мобильное приложение.

Кроме того, ИС должна предоставлять информацию необходимую как юридическим лицам, осуществляющим управление транспортной инфраструктурой города Москвы, так и бизнесу, заинтересованному, в получении актуальной информации из данной сферы, а также конечным пользователям общественного транспорта. Каждой из этих групп востребован доступ к необходимым им данным, тип и представления которых может существенно отличаться. В частности, для Департамента транспорта города Москвы в первую очередь необходим доступ к информации об актуальном значении интегральных критериев состояния транспортной инфраструктуры в целом, а для пассажиров в основном интересна информация о конкретном маршруте и даже конкретном транспортном средстве (его загруженности, времени прибытия и др.). Для этого должен быть реализован доступ пользователей к интересующей их информации в реальном времени.

Таким образом, при работе с ИС органы власти могут приниматься решения о постановке на загруженный маршрут большего количества общественного транспорта или же напротив снять с маршрута избыточные ресурсы, тем самым сбалансировав нагрузку на городскую транспортную инфраструктуру. Кроме того, актуальная информация о загруженности транспортной сети городской агломерации позволит принимать решение о необходимости изменений в инфраструктуре, например, таких как: расширении дорог на маршрутах или создание новых выделенных дорожных полос. Также, использование предлагаемой ИС дает государству возможность эффективно отслеживать количество граждан, которые не оплачивают свой проезд.

При работе с ИС юридические лица могут принимать решения об распространении рекламы своих товаров и услуг на самых популярных маршрутах и остановках, тем самым расширяя свой охват. Кроме того, маршрутные такси могут выходить на рейс на самые загруженные маршруты и в пиковые часы, тем самым увеличивая доход и уменьшая нагрузку на остальной транспорт. При работе с ИС водители такси смогут определять маршруты с наибольшим спросом на их услуги.

В свою очередь, пассажиры при работе с ИС смогут эффективно планировать свой маршрут, определяя не только местонахождения транспортных средств, но и их загруженность. В случае сильной загрузки транспорта пассажир может спланировать альтернативный маршрут до необходимого места назначения. Кроме того, у пассажира 
появляется возможность отследить наличие свободных мест в общественном транспорте и узнать их количество.

Для наиболее эффективного функционирования ИС необходимо организовать единое информационное пространство, в работу которого включены датчики оценки пассажиропотока различных типов. Поддержка информационной системой оборудования различных типов позволит осуществлять эффективную комплексную оценку необходимых параметров в реальном времени для всех видов общественного транспорта.

Конечно, сложность и цена реализации описанной концепции будет довольно высока, однако актуальность такой системы, как для государства и юридических лиц, так и для граждан - очевидна.

\section{Заключение}

В процессе исследования были рассмотрены основные особенности и проблемы развития транспортной инфраструктуры Московской агломерации. Отдельно была выделена проблема отсутствия единой информационной системы мониторинга пассажиропотоков агломерации в реальном времени, которая позволяла бы выстроить единое информационное пространство между государством, бизнесом и гражданами в транспортной сфере Москвы.

В статье были рассмотрены существующие технологии мониторинга пассажиропотоков городских агломераций систем «умного» города, а также описаны особенности их работы, преимущества и недостатки. Предложена концепция информационной системы мониторинга пассажиропотоков столичной агломерации в режиме реального времени. Предлагаемая система, должна обладать как веб сайтом, так и мобильным приложением для различных групп пользователей, как для государства и юридических лиц, так и для обычных граждан, которые смогут воспользоваться данными мониторинга для своих нужд. Таким образом, на наш взгляд, разработка и внедрение предложенной информационной системы наиболее актуальна в условиях развития транспортной инфраструктуры города Москвы и его агломерации.

В данной статье сформулирована концепция единой информационной системы мониторинга пассажиропотоков городской агломерации, взаимодействующая с транспортной инфраструктурой города, а также являющейся системой распределённого сбора данных с различных транспортных средств. Данная концепция была сформулирована, как основа для последующего проектирования информационной системы и её реализации Департаментом транспорта или стартапом для дальнейшего внедрения. В данной работе представлено обоснование разработки информационной системы, так как существующие разработки не покрывают все требования граждан, юридических лиц и государства.

\section{Литература}

[1] Ёлшина А.А. Городские агломерации: теоретические проблемы и анализ зарубежного опыта // Современные научные исследования и инновации, 2015. № 7. Ч. 3. URL: http://web.snauka.ru/issues/2015/07/56419 (дата обращения: 10.02.2019).

[2] Транспортная стратегия Российской Федерации на период до 2030 года URL: http://edu.tltsu.ru/sites/sites_content/site1977/html/media27851/2030_29_06_2008.pdf (дата обращения: 12.02.2019).

[3] Juniper research. Smart cities - what's in it for citizens? URL: https://newsroom.intel.com/wp-content/uploads/sites/11/2018/03/smart-cities-whats-in-itfor-citizens.pdf (дата обращения: 27.05.2019).

[4] McKinsey\&Company. Mckinsey Global Institute. Smart Cities: Digital solution for a more livable future. URL: https://www.mckinsey.com/ /media/mckinsey/industries/capital\%20pro 
jects $\% 20$ and $\% 20$ infrastructure/our $\% 20$ insights/smart $\% 20$ cities $\% 20$ digital $\% 20$ solutions $\% 20 \mathrm{f}$ or $\% 20 \mathrm{a} \% 20$ more $\% 20$ livable\%20future/mgi-smart-cities-full-report.ashx (дата обращения: 27.05.2019).

[5] Статистика Росстата по численности населения на 02.04.2018 год. URL: http://www.gks.ru/free_doc/new_site/population/demo/demo11.xls (Дата обращения: 12.02.2019).

[6] Безпалов В. В., Аносова М. Ю. Роль и возможности территориального планирования городских агломераций для реализации политики импортозамещения на современном этапе (на примере Московской агломерации) // Вопросы экономики и управления, 2016. №5. С. 15-19.

URL: https://moluch.ru/th/5/archive/44/1398/ (дата обращения: 12.02.2019).

[7] Оценка социально-экономического эффекта публикации открытых данных на примере данных общественного транспорта Москвы / Р. Е. Артамонов, С. Б. Датиев, А. Б. Жулин и др.; Нац. исслед. ун-т «Высшая школа экономики», Центр анализа деятельности органов исполнительной власти. - М: Изд. дом Высшей школы экономики, 2015. — 92 с. - 300 экз. — ISBN 978-5-7598-1266-1 (в обл.).

[8] Кельбах В.С. Транспортная инфраструктура как элемент городской агломерации // Вестник Санкт-Петербургского университета. Серия 7. Геология. 2013. вып. 2. URL: https://elibrary.ru/item.asp?id=19115688 (дата обращения: 10.02.2019).

[9] Постановление Правительства Москвы 28 марта 2017 г. №143-ПП «О внесении изменений в постановление Правительства Москвы от 2 сентября 2011 г. № 408-ПП». URL: https://www.mos.ru/upload/documents/docs/143-PP.pdf (дата обращения: 10.02.2019).

[10]Департамент Московского транспорта. Итоги работы Транспортного комплекса города Москвы за 2018 год и планы на 2019 год. URL: http://transport.mos.ru/\#!/page/mostrans/for_journs/presentations/presentations2018 (дата обращения: 12.02.2019).

[11]Раюшкин Э. С., Колесникова В. О., Куликов С. А., Раюшкина А. А. Моделирование распределения пассажиропотоков по различным видам общественного транспорта с учетом требований пассажиров // Молодой ученый. 2018. №8. C. 28-31. URL: https://moluch.ru/archive/194/48440/ (дата обращения: 10.02.2019).

[12] Компания «ПромСервис». Система мониторинга пассажироперевозок «Поток». URL: http://www.promservis.ru/sistema-monitoringa-passazhiroperevozok-potok.html (дата обращения: 10.02.2019).

[13] Компания «Евромобайл». Подсчет пассажиропотока. URL: https://www.euromobile.ru/solutions/transport/podschyot-passazhiropotoka/ (дата обращения: 12.02.2019).

[14] Компания «АльфаВладТелематика». Система подсчета пассажиров. URL: http://avladtel.ru/kontrol-passazhiropotoka/ (дата обращения: 12.02.2019).

[15]Флорова М.В. Применение веб-технологий при разработке распределённых систем мониторинга // Известия ЮФУ. Технические науки. 2011. № 5 (118)ю C. 41-47. URL: https://elibrary.ru/item.asp?id=16358768 (дата обращения: 10.05.2019). 


\title{
The Concept of an Information System for Monitoring Passenger Traffic in Urban Agglomerations
}

\author{
D.V. Petrova
}

\author{
MIREA - Russian Technological University
}

This article describes the concept of an information system for monitoring the passenger traffic of public transport in urban agglomerations. The specificity of the transport infrastructure of the Moscow metropolitan area, its features and main problems are considered. To solve the problems considered, it is proposed to develop and implement an information system for monitoring passenger traffic of the Moscow agglomeration. In addition, analogues of the proposed monitoring system are considered, as well as a list of the main indicators for monitoring passenger traffic and their application.

Keywords: information system, monitoring, passenger traffic, transport infrastructure, transport, urban agglomerations

Reference for citation: Petrova D.V. The Concept of an Information System for Monitoring Passenger Traffic in Urban Agglomerations // Information Society: Education, Science, Culture and Technologies of the Future. Vol. 3 (Proceedings of the XXII International Joint Scientific Conference «Internet and Modern Society», IMS-2019, St. Petersburg, June 19-22, 2019). St. Petersburg: ITMO University, 2019. P. 27 - 40. DOI: 10.17586/2587-8557-2019-3-27-40

\section{Reference}

[1] Yolshina A.A. Gorodskie aglomeracii: teoreticheskie problemy i analiz zarubezhnogo opyta // Sovremennye nauchnye issledovaniya i innovacii. 2015. № 7. CH. 3. URL: http://web.snauka.ru/issues/2015/07/56419 (data obrashcheniya: 10.02.2019).

[2] Transportnaya strategiya Rossijskoj Federacii na period do 2030 goda. URL: http://edu.tltsu.ru/sites/sites_content/site1977/html/media27851/2030_29_06_2008.pdf (data obrashcheniya: 12.02.2019).

[3] Juniper research. Smart cities - what's in it for citizens? URL: https://newsroom.intel.com/wp-content/uploads/sites/11/2018/03/smart-cities-whats-in-itfor-citizens.pdf (data obrashcheniya: 27.05.2019).

[4] McKinsey\&Company. Mckinsey Global Institute. Smart Cities: Digital solution for a more livable future. URL: https://www.mckinsey.com/ /media/mckinsey/industries/ capital $\% 20$ projects $\% 20$ and $\% 20$ infrastructure/our\%20insights/smart $\% 20$ cities $\% 20$ digital $\% 20$ solutions $\% 20$ for $\% 20 \mathrm{a} \% 20$ more $\% 20$ livable $\% 20$ future/mgi-smart-cities-full-report.ashx (data obrashcheniya: 27.05.2019).

[5] Statistika Rosstata po chislennosti naseleniya na 02.04.2018 god [EHlektronnyj resurs]. URL: http://www.gks.ru/free_doc/new_site/population/demo/demo11.xls (data obrashcheniya: 12.02.2019).

[6] Bezpalov V. V., Anosova M. YU. Rol' i vozmozhnosti territorial'nogo planirovaniya gorodskih aglomeracij dlya realizacii politiki importozameshcheniya na sovremennom ehtape (na primere Moskovskoj aglomeracii) // Voprosy ehkonomiki i upravleniya, 2016. №5. S. 15-19. URL: https://moluch.ru/th/5/archive/44/1398/ (data obrashcheniya: 12.02.2019).

[7] Ocenka social'no-ehkonomicheskogo ehffekta publikacii otkrytyh dannyh na primere dannyh obshchestvennogo transporta Moskvy / R. E. Artamonov, S. B. Datiev, A. B. ZHulin i dr.; Nac. issled. un-t «Vysshaya shkola ehkonomiki», Centr analiza deyatel'nosti organov 
ispolnitel'noj vlasti. — M: Izd. dom Vysshej shkoly ehkonomiki, 2015. — 92 s. — 300 ehkz. — ISBN 978-5-7598-1266-1 (v obl.).

[8] Kel'bah V.S. Transportnaya infrastruktura kak ehlement gorodskoj aglomeracii // Vestnik Sankt-Peterburgskogo universiteta. Seriya 7. Geologiya. Izdatel'stvo: Sankt-Peterburgskij gosudarstvennyj universitet (Sankt-Peterburg) ISSN: 1029-7456. URL: https://elibrary.ru/item.asp?id=19115688 (data obrashcheniya: 10.02.2019).

[9] Postanovlenie Pravitel'stva Moskvy 28 marta 2017 g. №143-PP «O vnesenii izmenenij v postanovlenie Pravitel'stva Moskvy ot 2 sentyabrya 2011 g. № 408-PP». URL: https://www.mos.ru/upload/documents/docs/143-PP.pdf (data obrashcheniya: 10.02.2019).

[10] Departament Moskovskogo transporta. Itogi raboty Transportnogo kompleksa goroda Moskvy za 2018 god i plany na 2019 god. URL: http://transport.mos.ru/\#!/page/mostrans/for_journs/presentations/presentations2018 (data obrashcheniya: 12.02.2019).

[11] Rayushkin EH. S., Kolesnikova V. O., Kulikov S. A., Rayushkina A. A. Modelirovanie raspredeleniya passazhiropotokov po razlichnym vidam obshchestvennogo transporta $\mathrm{s}$ uchetom trebovanij passazhirov // Molodoj uchenyj. - 2018. - №8. - S. 28-31. URL: https://moluch.ru/archive/194/48440/ (data obrashcheniya: 10.02.2019).

[12] Kompaniya «PromServis». Sistema monitoringa passazhiroperevozok «Potok». URL: http://www.promservis.ru/sistema-monitoringa-passazhiroperevozok-potok.html (data obrashcheniya: 10.02.2019).

[13] Kompaniya «Evromobajl». Podschet passazhiropotoka. URL: https://www.euromobile.ru /solutions/transport/podschyot-passazhiropotoka/ (data obrashcheniya: 12.02.2019).

[14]Kompaniya «Al'faVladTelematika». Sistema podscheta passazhirov. URL: http://avladtel.ru/kontrol-passazhiropotoka/ (data obrashcheniya: 12.02.2019).

[15]M. Florov The use of web technologies in the development of distributed monitoring systems // Izvestia SFU. TECHNICAL SCIENCES, ISSN: 1999-9429. URL: https://elibrary.ru/item.asp?id=16358768 (access date: 05.10.2019). 